\title{
CÁC YẾU TỐ ẢNH HƯởNG ĐẾN GIÁ CỔ PHIẾU CỦA NHŨ'NG DOANH NGHIỆP BẤT ĐỘNG SẢN NIÊM YẾT TRÊN TH! TRƯỜNG CHÚNG KHOÁN VIẸT NAM
}

\author{
PHẠM NGỌC VÂN \\ Khoa Tài chính - Ngân hàng, Trương Đại học Công nghiệp Thành phố Hồ Chí Minh \\ Phamngocvan@iuh.edu.vn
}

Tóm tắt. Bài viết này nghiên cứu sự tác động của các yếu tố tỷ lệ lạm phát (INF), thu nhập trên mỗi cổ phần (EPS), cổ tức trên mỗi cổ phần (DPS) và chỉ số giá vàng (DGP) đến giá cổ phiếu (SP) tại các doanh nghiệp ngành $\mathrm{B} Đ S$ được niêm yết trên SGDCK TP.HCM trong giai đoạn từ 2012 đến 2017.

Thông qua phương pháp xử lý dữ liệu bằng kỹ thuật hồi quy dữ liệu bảng, bài nghiên cứu tiến hành phân tích các yếu tố tác động đến giá cổ phiếu của 30 doanh nghiệp nhóm ngành BĐS được niêm yết trên SGDCK TP.HCM từ năm 2012 đến năm 2017.

Kết quả nghiên cứu chỉ ra rằng các yếu tố thu nhập trên mỗi cổ phần (EPS), cổ tức trên mỗi cổ phần (DPS) và chỉ số giá vàng (DGP) có tác động tới giá cổ phiếu (SP)

Từ kêt quả đó, tác giả đưa ra một số kiến nghị giúp cho các nhà đầu tư cũng như các doanh nghiệp ngành BĐS tại Việt Nam có cái nhìn toàn diện hơn đối với các yếu tố tác động đến giá cổ phiếu của các doanh nghiệp ngành BĐS để có các quyết định phù hợp nhất.

Từ khóa: Giá cổ phiếu, sở giao dịch chứng khoán, bất động sản

\section{FACTORS AFFECTING THE STOCK PRICES OF REAL ESTATE BUSINESSES LISTED ON VIETNAM'S STOCK MARKET}

\begin{abstract}
This research studies the impact of inflation rate (INF), earnings per share (EPS), dividend per share (DPS) and gold price index (DGP) to stock prices (SP) in real estate enterprises listed on Ho Chi Minh City Stock Exchange in the period from 2012 to 2017.

Through the data processing method using regression table data, the paper analyzes the factors affecting the stock prices of 30 real estate companies listed on stock exchanges. HCMC securities from 2012 to 2017.

Research results showed that earnings per share (EPS), dividends per share (DPS) and gold price index (DGP) have an impact on stock price (SP).

From that result, the author makes a number of recommendations to help investors as well as real estate businesses in Vietnam to have a more comprehensive view of the factors affecting stock prices of businesses. real estate businesses to make the most appropriate decisions
\end{abstract}

Keywords: Stock price, Stock exchange, real estate

\section{GIỚI THIỆU}

Kể từ khi được thành lập vào tháng 7 năm 2000, tính đến nay thị trường chứng khoán Việt Nam đã phát triển một cách mạnh mẽ với 731 công ty được niêm yết, giá trị vốn hóa gần 3.360 nghìn tỷ VND trên 2 sàn giao dịch HOSE và HNX tại thời điểm cuối năm 2017 [6]

Sau khi luật nhà ở và luật kinh doanh BĐS đi vào thực thi. Thị trường bất động sản đã thu hút được một lượng lớn vốn đầu tư trực tiếp nước ngoài với đa dạng các sản phẩm hướng đến nhiều phân khúc khác nhau trên thị trường, Từ đầu năm 2019 đến nay, nguồn vốn FDI vào lĩnh vực $\mathrm{BĐS} \mathrm{vẫn} \mathrm{tăng} \mathrm{trưởng} \mathrm{ổn}$ định, các nhà đầu tư liên tục rót vốn vào Việt Nam. Theo đó, tổng lượng vốn đầu tư trực tiếp nước ngoài vào lĩnh vực $\mathrm{BĐS}$ trong 8 tháng năm 2019 đạt 2,31 tỷ USD chiếm khoảng 10,2\% tổng số vốn FDI đăng ký đầu tư vào Việt Nam [11]. Doanh thu và lợi nhuận luôn đạt kết quả tốt. Cụ thể, có khoảng 78/95 cổ phiếu bất động sản (BĐS) niêm yết trên 3 sàn công bố báo cáo tài chính năm 2019. Kết quả cho thấy năm 2019 là một năm kinh doanh khá thuận lợi với các doanh nghiệp niêm yết với lợi nhuận trên 3 sàn tăng trưởng khoảng $18 \%$. Bên cạnh nhóm ngành ngân hàng tạo sức hút mạnh thì ngành $\mathrm{BĐS}$ cũng đã gặt hái 
được nhiều kết quả rất khả quan. Doanh thu của ngành BĐS trong năm đạt hơn 273 nghìn tỉ đồng, tăng $33,6 \% \%$ [9]. Từ đó có thể thấy thị trường $\mathrm{BĐS}$ Việt Nam hiện đang rất hấp dẫn nên đã thu hút sự quan tâm rất nhiều của các nhà đầu tư tham gia vào thị trường chứng khoán. Vì vậy, việc nghiên cứu những nhân tố tác động đến giá cổ phiếu của các doanh nghiệp ngành BĐS là vấn đề rất cần thiết trong thời gian tới. Với ý nghĩa trên, tác giả nghiên cứu đề tài: "Các yếu tố ảnh hưởng đến giá cổ phiếu của những doanh nghiệp bất động sản được niêm yết trên thị trường chứng khoán Việt Nam" nhằm làm rõ các nhân tố ảnh hưởng đển giá cổ phiếu của các doanh nghiệp bất động sản, từ đó đưa ra những nhận định và đề xuất nhằm góp phần phát triển thị trường chứng khoán nói chung và làm tăng giá cổ phiếu doanh nghiệp bất động sản nói riêng.

\section{CÁC MÔ HÌNH NGHIÊN CỨU VỀ GIÁ CỔ PHIẾU TRƯớC ĐÂY}

Việc nghiên cứu các yếu tố tác động đến giá cổ phiếu đã được khá nhiều tác giả nghiên cứu tại các nền kinh tế và khu vực khác nhau. Lược khảo kết quả các nghiên cứu trước có liên quan như: $\mathrm{Al}$-Tamimi và ctv (2007), Umar Gunu và Ishiak Othman Idris (2009), Sanjeet sharma (2011), Nguyễn Minh Kiều, Nguyễn Văn Điệp (2013), Trương Đông Lộc (2014), Bùi Kim Yến và Nguyễn Thái Sơn (2014. Tác giả tổng hợp lại các nhân tố tác động đến giá cổ phiếu của các mô hình nghiên cứu trước vào bảng 1 dưới đây.

Bảng 1. Tổng hợp kết quả các nghiên cứu trước

\begin{tabular}{|c|c|c|c|c|}
\hline TT & Năm & Mô hình thực nghiệm & Tên biến & Dấu ảnh hưởng \\
\hline 1 & 2007 & Al-Tamimi và ctv & $\begin{array}{l}\text { EPS: Thu nhập mỗi cổ phần } \\
\text { M1: Cung tiền } \\
\text { IR: Lãi suất } \\
\text { CPI: Chỉ số giá tiêu dung } \\
\text { GDP: Tổng sản phẩm quốc nội }\end{array}$ & $\begin{array}{l}+ \\
\text { Không ý nghĩa } \\
\text { Không ý nghĩa } \\
- \\
\text { Không ý nghĩa }\end{array}$ \\
\hline 2 & 2009 & $\begin{array}{l}\text { Umar Gunu và Ishiak } \\
\text { Othman Idris }\end{array}$ & $\begin{array}{l}\text { M1: Cung tiền } \\
\text { IR: Lãi suất } \\
\text { CPI: Chỉ số giá tiêu dung } \\
\text { IIP (chỉ số sản xuất công nghiệp) } \\
\text { TD (tồng thâm hụt) }\end{array}$ & $\begin{array}{l}+ \\
+ \\
- \\
- \\
+\end{array}$ \\
\hline 3 & 2011 & Sanjeet Sharma & $\begin{array}{l}\text { EPS: Thu nhập mỗi cổ phần } \\
\text { DPS (cố tức trên mối cổ phiếu) } \\
\text { DP (tỷ lệ chia cổ tức) } \\
\text { BV (giá trị sổ sách trên mỗi cổ phiếu) } \\
\text { P/E (hệ số giá trên lợi nhuận) } \\
\text { Size (quy mô của công ty) }\end{array}$ & $\begin{array}{c}+ \\
+ \\
\text { Không ý nghĩa } \\
+ \\
\text { Không ý nghĩa } \\
\text { Không ý nghĩa }\end{array}$ \\
\hline 4 & 2013 & $\begin{array}{l}\text { Nguyễn Minh Kiều, } \\
\text { Nguyễn Văn Điệp }\end{array}$ & $\begin{array}{l}\text { M1: Cung tiền } \\
\text { CPI: Chỉ số giá tiêu dung } \\
\text { EX (tỷ giá hối đoái) } \\
\text { DGP (giá vàng) } \\
\text { EX }\end{array}$ & $\begin{array}{c}+ \\
\text { Không ý nghĩa } \\
+ \\
+ \\
+\end{array}$ \\
\hline 5 & 2014 & $\begin{array}{l}\text { Bùi Kim Yến và Nguyễn } \\
\text { Thái Sơn }\end{array}$ & $\begin{array}{l}\text { M1: Cung tiền } \\
\text { IR: Lãi suất } \\
\text { CPI: Chỉ số giá tiêu dùng } \\
\text { EX (tỷ giá hối đoái) }\end{array}$ & $\begin{array}{c}\text { Không ý nghĩa } \\
+ \\
- \\
+\end{array}$ \\
\hline 6 & 2014 & Trương Đông Lộc & $\begin{array}{l}\text { EPS: Thu nhập mỗi cổ phần } \\
\text { IR: Lãi suất } \\
\text { CPI: Chỉ số giá tiêu dùng } \\
\text { EX (tỷ giá hối đoái) } \\
\text { DGP (giá vàng) }\end{array}$ & $\begin{array}{c}+ \\
\text { Không ý nghĩa } \\
- \\
+ \\
-\end{array}$ \\
\hline
\end{tabular}

$(+)$ : Biến có tương quan thuận với chỉ số giá cổ phiếu

Nguồn: Tổng hợp từ các nghiên cứu trước

(-): Biến có tương quan nghịch với chỉ số giá cố phiếu

Các nghiên cứu được tiến hành vào những thời gian khác nhau, tại các quốc gia khác. Do đó, sự khác biệt về vùng miền và môi trường kinh tế sẽ cho những kết quả nghiên cứu riêng biệt. Từ các mô hình nghiên 
cứu này, tác giả sẽ chọn ra những biến phù hợp với thị trường chứng khoán Việt Nam để thực hiện việc phân tích và kiểm định ảnh hưởng của các nhân tố tác động đến giá cổ phiếu của doanh nghiệp bất động sản được niêm yết trên sở giao dịch chứng khoán TP.HCM

\section{PHƯOONG PHÁP NGHIÊN CÚU}

\subsection{Dữ liệu nghiên cứu}

Dữ liệu được lấy từ các báo cáo tài chính của các doanh nghiệp bất động sản được niêm yết tại sở giao dịch chứng khoáng TP.HCM. Riêng các nhân tố vĩ mô được lấy từ số liệu thống kê của World Bank và Tổng cục thống kê. Mẫu quan sát được thu thập trong khoảng thời gian từ tháng $1 / 2012$ đến tháng 12/2017. Tính thời thời điểm tháng 12/2017 có 30 doanh nghiệp bất động sản được niêm yết tại sở giao dịch chứng khoán TP.HCM.

Áp dụng theo công thức của Tabachnick \& Fidell (2007), với số biến độc lập là 5 vậy kích thước mẫu tối thiểu là 109 . Với việc chọn 30 doanh nghiệp bất động sản để nghiên cứu trong giai đoạn từ tháng $1 / 2012$ đến tháng $12 / 2017$, tổng mẫu thu được là 180 . Với kết quả này, kích thước mẫu phù hợp với công thức của Tabachnick \& Fidell (2007), đủ khả năng để tiến hành phân tích hồi quy và kết quả phân tích đủ độ tin cậy cho các kết luận khoa học.

\subsection{Mô hình nghiên cứu}

Dựa vào những kết quả nghiên cứu trước đây của các mô hình nghiên cứu các nhân tố tác động đến giá cổ phiếu trên thế giới cũng như trong nước. Để phù hợp với hoạt động kinh doanh BĐS và trong giai đoạn hiện nay tại Việt Nam. Tác giả đề xuất mô hình với những nhân tố sau để tiến hành nghiên cứu:

$$
\mathrm{SP}_{\mathrm{i}, \mathrm{t}}=\boldsymbol{\beta}_{0}+\boldsymbol{\beta}_{1} \mathrm{INF}_{\mathrm{t}}+\boldsymbol{\beta}_{2} \mathrm{DGP}_{\mathrm{t}}+\boldsymbol{\beta}_{3} \mathrm{EPS}_{\mathrm{t}}+\beta_{4} \mathrm{DPS}_{\mathrm{i}, \mathrm{t}}+\varepsilon_{\mathrm{i}, \mathrm{t}}
$$

Trong đó: Biến phụ thuộc $\mathrm{SP}_{\mathrm{i}, \mathrm{t}}$ : Giá cổ phiếu của doanh nghiệp i năm $\mathrm{t}$

Các biến độc lập: $\mathrm{INF}_{\mathrm{t}}$ : Tỷ lệ lạm phát thời điểm $\mathrm{t}$; $\mathrm{DGP}_{\mathrm{t}}$ : Giá vàng thời điểm $\mathrm{t} ; \mathrm{EPS}_{\mathrm{i}, \mathrm{t}}$ : Thu nhập trên mỗi cổ phần của doanh nghiệp $\mathrm{i}$ thời điểm $\mathrm{t}$; $\mathrm{DPS}_{\mathrm{i}, \mathrm{t}}$ : Cổ tức trên mỗi cổ phần của doanh nghiệp $\mathrm{i}$ thời điểm $\mathrm{t} ; \boldsymbol{\beta}_{1}$ : Là hệ số hồi quy đo lường mức thay đổi của SP trên một đơn vị thay đổi của CPI khi mà giá trị của DGP, EPS, DPS là không đổi.; $\boldsymbol{\beta}_{2}$ : Là hệ số hồi quy đo lường mức thay đổi của SP trên một đơn vị thay đổi của DGP khi mà giá trị của INF, EPS, DPS là không đổi.; $\boldsymbol{\beta}_{3}$ : Là hệ số hồi quy đo lường mức thay đổi của SP trên một đơn vị thay đổi của EPS khi mà giá trị của INF, DGP, DPS là không đổi.; $\boldsymbol{\beta}_{4}$ : Là hệ số hồi quy đo lường mức thay đổi của SP trên một đơn vị thay đổi của DPS khi mà giá trị của INF, DGP, EPS là không đổi.; $\boldsymbol{\varepsilon}_{\mathrm{i}, \mathrm{t}}$ : Sai số ngẫu nhiên.

a. Đo lường các biến ảnh hưởng đến giá cổ phiếu của những doanh nghiệp bất động sản được niêm yết trên thị trường chứng khoán Việt Nam

\section{Lam phát (INF).}

Bằng chứng thực nghiệm ở Việt Nam cho thấy trong giai đoạn 2007-2008, giai đoạn 2010-2011 khi mà tỷ lệ lạm phát cao với 2 con số, giá trị cổ phiếu trên thị trường chứng khoán liên tục sụt giảm, một bức tranh kinh tế ảm đạm bao trùm lên toàn nền kinh tế. Từ đó cho thấy lạm phát và giá cổ phiếu có mối quan hệ nghịch biến với nhau. Điều này hoàn toàn phù hợp với kết quả nghiên cứu thực nghiệm của Trương Đông Lộc (2014), Nguyễn Minh Kiều, Nguyễn Văn Điệp (2013), Al-Tamimi và ctv (2007),

Tỷ lệ lạm phát $=\left(\mathrm{CPI}_{\mathrm{t}}-\mathrm{CPI}_{\mathrm{t}-1}\right) / \mathrm{CPI}_{\mathrm{t}-1}$

Trong đó: $\mathrm{CPI}$ : Chỉ số giá tiêu dùng năm $\mathrm{t}$

$$
\mathrm{CPI}_{\mathrm{t}-1} \text { : Chỉ sô giá tiêu dùng năm } \mathrm{t}-1
$$

\section{Giả thuyết H1: Lạm phát có tác động ngược chiều với giá cổ phiếu}

\section{Giá vàng (DGP)}

Vàng khác với các tài sản khác bởi vì tiềm năng đối với vàng là tính thanh khoản cao và nó phản ứng với những thay đổi giá. Sự biến động của giá vàng ảnh hưởng đến phần lớn các nền kinh tế trên thế giới trong đó có thị trường chứng khoán. Các nhà đầu tư có thói quen sử dụng chiến lược quản trị rủi ro đơn giản là đa dạng hóa trong danh mục đầu tư của họ các hàng hóa có cả đầu tư vàng hoặc dầu vì hai khoản đầu tư này thường có mối quan hệ nghịch đảo với xu huớng của thị trường chứng khoán.

Cũng theo Trương Đông Lộc (2014) giá vàng có mối quan hệ nghịch chiều với giá cổ phiếu. Các mô hình trước đây cũng chỉ ra rằng với các nền kinh tế mới nổi thì giá vàng và giá cổ phiếu là 2 đại lượng nghịch biến. Điều này thì phù hợp với thực trạng nền kinh tế Việt Nam hiện nay. 


\section{Giả thuyết H2:Giá vàng có tác động ngược chiều với giá cổ phiếu}

\section{Thu nhập trên mỗi cổ phần (EPS)}

* Thu nhập trên mỗi cổ phần (EPS) thường được tính theo công thức:

Thu nhập trên mỗi cổ phần = Lợi nhuận sau thuế / Số lương cổ phần

EPS thường được coi là biến số quan trọng duy nhất trong việc tính toán giá cổ phiếu. EPS đánh giá khả năng hoạt động của doanh nghiệp, là một trong những chỉ tiêu được sử dụng thường xuyên nhất đối với các nhà đầu tư và có ảnh hưởng lớn đối với giá cổ phiếu công ty.

Theo mô hình nghiên cứu về các nhân tố ảnh hưởng đến giá cổ phiếu của Trương Đông Lộc (2014), Sanjeet sharma (2011 đều cho rằng. EPS và giá cổ phiếu có mối quan hệ cùng chiều. Sanjeet sharma (2011) còn chỉ ra rằng thu nhập trên mỗi cổ phiếu và cổ tức trên mỗi cổ phiếu là yếu tố quyết định mạnh nhất của giá cả thị trường.

\section{Giả thuyết H3:EPS có tác động cùng chiều với giá cổ phiếu}

Cổ tức trên mổi cổ phần (DPS)

Cổ tức trên mỗi cổ phiếu là phần thu nhập mà nhà đầu tư nhận được khi mua cổ phiếu. Cổ tức trên mỗi cổ phiếu được tính theo công thức sau:

Cổ tức trên mỗi cổ phần = Thu nhập trên mỗi cổ phần*Tỷ lệ chi trả cổ tức

Theo nghiên cứu của Sanjeet sharma (2011) thì cổ tức trên mỗi cổ phần là yếu tố có quyết định quan trọng đến giá cổ phiếu và có quan hệ cùng chiều với giá cổ phiếu. Điều này phù hợp về mặt lý thuyết cũng như thực tiễn tại thị trường chứng khoán VN.

\section{Giả thuyết H4: DPS có tác động cùng chiều với giá cổ phiếu}

Bảng 2. Bảng mô tả các biến giải thích, đo lường và giả thuyết

\begin{tabular}{|c|c|c|c|c|c|}
\hline TT & Năm & Mô hình thực nghiệm & Biến & Đo lường & $\begin{array}{l}\text { Kỳ } \\
\text { vọng }\end{array}$ \\
\hline \multicolumn{6}{|c|}{ Biến phụ thuộc } \\
\hline & & & SP & Giá đóng cửa bình quân năm & \\
\hline \multicolumn{6}{|c|}{ Biến độc lập } \\
\hline \multirow[t]{2}{*}{1} & \multirow[t]{2}{*}{2007} & \multirow[t]{2}{*}{ Al-Tamimi và ctv } & INF & $\begin{array}{l}\text { Chỉ số giá tiêu dùng (\%) do tồng cục thống kê } \\
\text { thông báo }\end{array}$ & $(-)$ \\
\hline & & & EPS & $\begin{array}{l}\text { (Lợi nhuận sau thuế - cổ tức cổ phiếu ưu } \\
\text { đãi)/Số lượng CP thường }\end{array}$ & $(+)$ \\
\hline 2 & 2011 & Sanjeet sharma & DPS & Thu nhập trên mổi cổ phần*Tỷ lệ chia cổ tức & $(+)$ \\
\hline 3 & 2013 & $\begin{array}{l}\text { Nguyễn Minh Kiều và } \\
\text { Nguyễn Văn Điệp }\end{array}$ & INF & $\begin{array}{l}\text { Chỉ số giá tiêu dùng (\%) do tồng cục thống kê } \\
\text { thông báo }\end{array}$ & $(-)$ \\
\hline \multirow{3}{*}{4} & \multirow{3}{*}{2014} & \multirow{3}{*}{ Trương Đông Lộc } & INF & $\begin{array}{l}\text { Chỉ số giá tiêu dùng (\%) do tổng cục thống kê } \\
\text { thông báo }\end{array}$ & $(-)$ \\
\hline & & & DGP & $\begin{array}{l}\text { Chỉ số giá vàng (\%) do tổng cục thống kê } \\
\text { thông báo }\end{array}$ & $(-)$ \\
\hline & & & EPS & $\begin{array}{l}\text { (Lợi nhuận sau thuế - cổ tức cổ phiếu ưu } \\
\text { đãi)/Số lượng CP thường }\end{array}$ & $(+)$ \\
\hline
\end{tabular}

\subsection{Phương pháp nghiên cứu}

Nguồn: Tổng hợp của tác giả

Bài nghiên cứu sử dụng phần mềm phân tích STATA 12. Trình tự xử lý số liệu gồm thống kê mô tả dữ liệu, khảo sát các cặp tương quan giữa các biến, kiểm định hiện tượng đa cộng tuyến thông qua chỉ số VIF, tiến hành chạy hồi quy với 3 mô hình: Mô hình POOL, mô hình FEM và mô hình REM, kiểm định để lựa chọn mô hình phù hợp thông qua kiểm định $\mathrm{F}$ test và Hausman test. Sau khi lựa chọn mô hình phù hợp sẽ tiển hành kiểm định phương sai của sai số không đổi thông qua kiểm định White, kiểm định tự tương quan bằng Wooldridge test, khắc phục hiện tượng tự tương quan và phương sai của sai số không đổi bằng phương pháp bình phương bé nhất tổng quát khả thi FGLS để đưa ra kết quả cuối cùng và lựa chọn mô hình phù hợp. 


\section{KẾT QUẢ NGHIÊN CÚ̉ VÀ THẢO LUẬN}

\subsection{Mô tả mẫu nghiên cứu}

Dữ liệu được thu thập từ 30 doanh nghiệp nhóm ngành bất động sản được niêm yết trên sở giao dịch chứng khoáng TP.HCM trong giai đoạn từ 2012 -2017 được thể hiện ở bảng 3 sau:

Bảng 3. Thống kê mô tả các biến trong mô hình

\begin{tabular}{|c|c|c|c|c|c|}
\hline Tên biến & Số quan sát & $\begin{array}{c}\text { Giá trị trung } \\
\text { binh }\end{array}$ & $\begin{array}{c}\text { Độ lệ̉ch } \\
\text { chuẩn }\end{array}$ & Giá trị nhỏ nhất & Giá trị lớn nhất \\
\hline SP & 180 & $10.527,88$ & $7.705,699$ & $1.679,773$ & $42.542,33$ \\
\hline INF & 180 & 0,0377 & 0,0226 & 0,006 & 0,0681 \\
\hline DGP & 180 & $-0,0282$ & 0,1104 & $-0,2436$ & 0,1098 \\
\hline EPS & 180 & $835,163,9$ & $1.537,31$ & -5.038 & 7.032 \\
\hline DPS & 180 & 478,1056 & 911,5032 & 0 & 6.400 \\
\hline
\end{tabular}

\subsection{Phân tích tương quan giữa các biến và kiểm định đa cộng tuyến}

Nguồn: Trích từ dữ liệu nghiên cứu

Bảng 4 thể hiện ma trận hệ số tương quan, việc phân tích tương quan cho ta thấy mức tương quan giữa các biến trong mô hình nghiên cứu. Đồng thời trình bày về chỉ số VIF (Variance Inflation Factor) để kiểm tra khả năng có thể xuất hiện hiện tượng đa cộng tuyến giữa các biến trong mô hình.

Bảng 4. Ma trận hệ số tương quan giữa các biến và kiểm định đa cộng tuyến

\begin{tabular}{|lllllll|}
\hline & SP & INF & DGP & EPS & DPS & VIF \\
\hline SP & 1 & & & & & \\
\hline INF & $-0,1543$ & 1 & & & & 1,04 \\
\hline DGP & 0,2610 & $-0,1746$ & 1 & & & 1,05 \\
\hline EPS & 0,5508 & $-0,0895$ & 0,1285 & 1 & & 1,41 \\
\hline DPS & 0,4044 & $-0,0838$ & $-0,0005$ & 0,5254 & 1 & 1,39 \\
\hline
\end{tabular}

Nguồn: Trích từ dữ liệu nghiên cứu

Dựa vào bảng 4 ta thấy các biến độc lập DGP, EPS và DPS có tác động cùng chiều đến biến phụ thuộc $\mathrm{SP}$, chỉ duy nhất biến INF là có tác động nghịch chiều với biến phụ thuộc.

Bảng 4 cũng cho thấy giữa biến EPS và DPS có mối tương quan mạnh nhất với kết quả 0.5254 . Tuy nhiên kết quả này không gây ra hiện tượng tự tương quan nghiêm trọng do các hệ số tương quan có giá trị khá thấp (chuẩn so sánh theo Farrar \& Glauber (1967) là 0.8).

Theo Gujarati (2004) nếu chỉ số VIF lớn hơn 5, đó là dấu hiệu cho thấy có hiện tượng đa cộng tuyến cao, nếu chỉ số này lớn hơn 10 là dấu hiệu cho thấy có hiện tượng đa cộng tuyến nghiêm trọng. Với giá trị lớn nhất là 1,41 , có thể thấy rằng khả năng xảy ra hiện tượng đa cộng tuyến trong mô hình là không đáng kể. Qua phân tích, không có hiện tượng đa công tuyến cũng như tự tương quan giữa các biến độc lập, vì vậy không cần loại bỏ biển độc lập nào ra khỏi mô hình trước khi ước lượng hồi quy.

Kết quả phân tích mô hình hồi quy và các kiểm định

Bảng 5. Kết quả phân tích hồi quy

\begin{tabular}{|c|c|c|c|c|c|c|}
\hline \multirow[b]{2}{*}{ Biến } & \multicolumn{2}{|c|}{ Pooled OLS } & \multicolumn{2}{|c|}{ FEM } & \multicolumn{2}{|c|}{ REM } \\
\hline & $\begin{array}{l}\text { Hệ số hồi quy } \\
\text { (Coef.) }\end{array}$ & $\begin{array}{c}\text { Mức ý } \\
\text { nghĩa } \\
(\mathbf{P}>|\mathbf{t}|)\end{array}$ & $\begin{array}{l}\text { Hệ số hồi quy } \\
\text { (Coef.) }\end{array}$ & $\begin{array}{c}\text { Mức ý } \\
\text { nghĩa } \\
(\mathrm{P}>|\mathbf{t}|)\end{array}$ & $\begin{array}{l}\text { Hệ số hồi quy } \\
\text { (Coef.) }\end{array}$ & $\begin{array}{c}\text { Mức ý } \\
\text { nghĩa } \\
(\mathbf{P}>|\mathbf{t}|)\end{array}$ \\
\hline INF & -23.007 & 0,273 & $-31.524 *$ & 0,035 & -28.262 & 0,059 \\
\hline DGP & $13.553 * *$ & 0,002 & $14.822 * * *$ & 0,000 & $14.324 * * *$ & 0,000 \\
\hline EPS & $2,1481 * * *$ & 0,000 & $1,2657 * * *$ & 0,000 & $1,6101 * * *$ & 0,000 \\
\hline DPS & $1,4685^{*}$ & 0,015 & 0,2162 & 0,694 & 0,6871 & 0,183 \\
\hline Cons & $9.282,2 * * *$ & 0,000 & $10.975 * * *$ & 0,000 & $10.325 * * *$ & 0,000 \\
\hline $\mathrm{R}^{2}$ hiệu chỉnh & \multicolumn{2}{|c|}{0,3529} & \multicolumn{2}{|c|}{0,2844} & \multicolumn{2}{|c|}{0,2783} \\
\hline $\begin{array}{l}\text { F-statistic } \\
\text { /Wald.Chi2 }\end{array}$ & \multicolumn{2}{|c|}{25,41} & \multicolumn{2}{|c|}{14,51} & \multicolumn{2}{|c|}{73,21} \\
\hline P-value & \multicolumn{2}{|c|}{0,0000} & \multicolumn{2}{|c|}{0,0000} & \multicolumn{2}{|c|}{0,0000} \\
\hline
\end{tabular}

Ghi chú:

Nguồn: Trích từ dữ liệu nghiên cứu 
(*) : Mức ý nghĩa thống kê $10 \%$

(**) : Mức ý nghĩa thống kê $5 \%$

(***) : Mức ý nghĩa thống kê 1\%

4.3. Lựa chọn mô hình

\section{Lựa chọn giữa mô hình FEM và POOL:}

Ta có các giả thuyết $\quad \mathrm{H}_{0}$ : Mô hình phù hợp là $\mathrm{POOL}$

$\mathrm{H}_{1}$ : Mô hình phù hợp là FEM

Dựa vào kết quả kiểm định $\mathrm{F}$ ở bảng 4.3 , với mức ý nghĩa $5 \%$, ta có $\mathrm{F}=0.0000<5 \%$. Bác bỏ giả thuyết $\mathrm{H}_{0}=>$ chọn mô hình FEM.

Lựa chọn mô hình FEM hay REM sử dụng kiểm định Hausman để xem xét có tồn tại tự tương quan giữa $\varepsilon_{\mathrm{i}}$ và các biến độc lập hay không.

Giả thiết:

$\mathrm{H}_{0}$ : $\varepsilon_{\mathrm{i}}$ và biến độc lập không tương quan

$\mathrm{H}_{1}: \varepsilon_{\mathrm{i}}$ và biến độc lập có tương quan

Khi giá trị $\mathrm{P}<0.05$ ta bác bỏ $\mathrm{H}_{0}$, khi đó $\varepsilon_{\mathrm{i}}$ và biến độc lập tương quan với nhau, ta sử dụng mô hình tác động cố định (FEM). Ngược lại, ta sử dụng mô hình tác động ngẫu nhiên (REM).

Bảng 6 Kiểm định Hausman

\begin{tabular}{|l|c|c|}
\hline \multirow{2}{*}{ Kiểm định Hausman } & Chi2 & Prob>chi2 \\
\cline { 2 - 3 } & 6,41 & 0,0925 \\
\hline
\end{tabular}

Nguồn: Trích từ dữ liệu nghiên cứu

Qua kết quả kiếm định ở bảng 4.4 , ta thấy Prob $=0,0925>0,05$ vì vậy chấp nhận giả thuyết $\mathrm{H}_{0}$, mô hình tác động ngẫu nhiên REM thì phù hợp hơn mô hình tác động cố định FEM.

Thông qua các kiểm định, REM là mô hình được lựa cọn. Tiếp đến ta sẽ tiến hành các kiểm định để kiếm tra xem mô hình tác động ngẫu nhiên REM có bị các khuyết tật không, để đảm bảo rằng các ước lượng thu được bền vững và hiệu quả nhất.

Kiểm định các giả thuyết hồi quy

Kiểm định phương sai của sai số không đổi

Kiểm định giả thuyết phương sai của sai số không đổi bằng kiểm định nhân tử Lagrange mô hình REM, với giả thuyết $\mathrm{H}_{0}$ : Không có hiện tượng phương sai thay đổi.

Bảng 7 Kiểm định Lagrange mô hình REM

\begin{tabular}{|c|c|}
\hline Chibar2(01) & 98,23 \\
\hline Prob.Chibar2 & 0,0000 \\
\hline
\end{tabular}

Với mức ý nghĩa $\alpha=5 \%$, kiểm định nhân tử Lagrange cho mô hình REM có kết quả là Prob $=0,0000$. Vậy, Prob $<5 \%$ nên bác bỏ giả thuyết $\mathrm{H}_{0}$, có hiện tượng phương sai của sai số thay đổi.

Kiềm định tự tương quan của sai số

Nghiên cứu tiến hành kiểm định giả thuyết không bị tự tương quan trên dữ liệu bảng, với giả thuyết $\mathrm{H}_{0}$ : không có sự tự tương quan.

Bảng 4.6 Kiểm định tự tương quan của sai số

\begin{tabular}{|c|}
\hline Wooldridge test for autocorrelation in panel data \\
\hline $\mathrm{H}_{0}$ : no first order autocorrelation \\
\hline $\mathrm{F}(1,29)=11,413$ \\
\hline $\mathrm{Prob}>\mathrm{F}=0,0021$ \\
\hline
\end{tabular}

Với mức ý nghĩa $\alpha=5 \%$, kiểm định cho kết quả là: Prob $=0,0021$

Nguồn: Dữ liệu nghiên cứu trích từ phụ lục

Vậy, Prob $<0,05$ nên bác bỏ giả thuyết $\mathrm{H}_{0}$, Có hiện tượng tự tương quan của sai số trong mô hình.

\section{Tổng hợp kết quả kiểm định}

Sử dụng phương pháp bình phương bé nhất tổng quát khả thi (Feasible General Least Square - FGLS). Phương pháp này thực chất là phương pháp bình phương bé nhất thông thường (OLS) áp dụng cho các biến đã được biến đổi từ một mô hình vi phạm các giả thiết cổ điển thành một mô hình mới thỏa các giả thiết cổ điển. Do đó các tham số ước lượng được từ mô hình mới sẽ đáng tin cậy hơn. 
Bảng 8. Phương pháp bình phương bé nhất tổng quát khả thi (Feasible General Least Square - FGLS)

\begin{tabular}{|c|c|c|c|}
\hline Biến & Hệ số hồi quy & Giá trị t & Giá trị P-value \\
\hline INF & $-23.006,73$ & $-1,12$ & 0,264 \\
\hline DGP & $13.552,93$ & 3,19 & 0,001 \\
\hline EPS & 2,1481 & 6,08 & 0,000 \\
\hline DPS & 1,4685 & 2,48 & 0,013 \\
\hline Cons & $9.282,196$ & 9,70 & 0,000 \\
\hline Số quan sát & \multicolumn{3}{|c|}{180} \\
\hline Wald-chi2 & \multicolumn{3}{|c|}{$0,04,53$} \\
\hline Prob > chi2 & \multicolumn{3}{|c|}{} \\
\hline
\end{tabular}

Nguồn: Dữ liệu nghiên cứu trích từ phụ lục

Với biến phụ thuộc là $\mathrm{SP}_{\mathrm{i}, \mathrm{t}}$, sau khi dùng phương pháp FGLS để khắc phục hiện tượng tự tương quan giữa các sai số để đảm bảo ước lượng thu được vững và hiệu quả, ta có kết quả như sau:

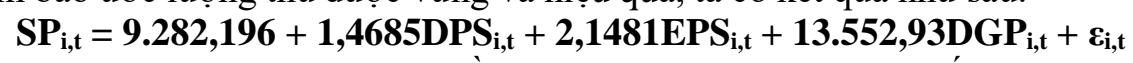

- Biến tỷ giá vàng (DGP) có tác động cùng chiều $(13.552,93)$ và có ý nghĩa thống kê với mức ý nghĩa $5 \%$.

- Biến thu nhập trên mỗi cổ phần (EPS) có tác động cùng chiều $(2,1481)$ và có ý nghĩa thống kê với mức ý nghĩa $5 \%$.

- Biến cổ tức mỗi cổ phiếu (DPS) tác động cùng chiều $(1,4685)$ và có ý nghĩa thống kê với mức ý nghĩa $5 \%$.

- Biến tỷ lệ lạm phát (INF) có tác động ngược chiều nhưng không tìm thấy tác động có ý nghĩa thống kê với bộ dữ liệu thu thập được ở mức ý nghĩa $5 \%$.

\section{THẢO LUẬN KẾT QUẢ NGHIÊN CÚU \\ Biến tỷ lệ lạm phát (INF)}

Với mức ý nghĩa $5 \%$ biến tỷ lệ lạm phát $\left(\mathrm{INF}_{\mathrm{i}, \mathrm{t}}\right)$ không có ý nghĩa thống kê, nên chưa đủ cơ sở để kết luận tỷ lệ lạm phát có tác động tới giá cổ phiếu của các cổ phiếu thuộc nhóm ngành công nghiệp trong giai đoạn từ năm 2012-2017. Điều này có thể giải thích rằng ở paper gốc thì tỷ lệ lạm phát có ảnh hưởng tiêu cực đến giá cổ phiếu, nhưng thực tế ở thị trường Việt Nam trong giai đoạn này chính phủ vẫn luôn duy trì tỷ lệ lạm phát một cách ổn định nên hầu như những tác động của nó đến giá cổ phiếu thì không đáng kể. Tỷ lệ lạm phát (INF) chỉ ảnh hưởng nhiều đến thị trường chứng khoán ở giai đoạn giá cả tăng mạnh, bất ổn định vĩ mô.

\section{Biến giá vàng (DGP)}

Kết quả nghiên cứu cho thấy tỷ giá vàng và giá cổ phiếu có mối tương quan cùng chiều với nhau ở mức ý nghĩa $5 \%$. Mối tương quan này chỉ ra rằng tỷ giá vàng càng tăng thì giá cổ phiếu càng tăng và ngược lại. Kết quả này phù hợp với các nghiên cứu của Nguyễn Minh Kiều, Nguyễn Văn Điệp (2013).

Kết quả nghiên cứu này thì không phù hợp với giả thuyết được đưa ra từ đầu là tỷ giá vàng và giá cổ phiếu có tác động ngược chiều. Ta có thể thấy được những tác động ngược chiều của giá vàng đến giá cổ phiếu trong ngắn hạn một cách mạnh mẽ, tuy nhiên trong dài hạn kết quả này lại ngược lại. Cất trữ vàng là thói quen nhiều đời của người dân Việt Nam, bất kể người già hay trẻ, cứ có vàng trong nhà là thấy yên tâm. Có thể nói rằng, cuộc sống người Việt Nam đã gắn khá chặt với kim loại quý này, điều này làm cho nhu cầu về vàng tăng theo tốc độ tăng trưởng của nền kinh tế cũng như khả năng tích lũy của người dân. Theo số liệu dự báo của Hiệp hội vàng Việt Nam năm 2016 hiện có khoảng 500 tấn vàng trong dân, như vậy vàng vẫn luôn là một sự lựa chọn trong danh mục đầu tư của nhà đầu tư cùng với các tài sản khác và sự biến động cùng chiếu với giá cổ phiếu là một kết quả khác biệt so với các nghiên cứu thực nghiệm trước đây do những nét riêng về thói quen, đặc thù nền kinh tế ở Việt Nam.

\section{Biến thu nhập trên mối cổ phần (EPS)}

Kết quả nghiên cứu cho thấy biến EPS và DPS có mối tương quan cùng chiều với nhau ở mức ý nghĩa $5 \%$. Mối tương quan này chỉ ra rằng EPS tăng thì DPS sẽ tăng lên và ngược lại. Kết quả này phù hợp với các nghiên cứu trước đây và với giả thuyết đã được đặt ra từ đầu. EPS là nhân tố tác động trực tiếp đến sự biến động DPS của một công ty. Chính vì vậy, doanh nghiệp cấn có kế hoạch và chiến lược phát triển 
kinh doanh tốt, tối đa hóa lợi nhuận, cắt giảm chi phí không cần thiết, như vậy cổ phiếu của mình mới có sức hấp dẫn các nhà đầu tư. Tuy là một yếu tố quan trọng đến giá cổ phiếu và thông thường đối với đa số nhà đầu tư song thực tế ở Việt Nam hình như không có ai mua cổ phiếu để mong nhận được lợi tức từ cổ phiếu, nhưng ngược lại vẫn xem xét EPS của cổ phiếu nào cao hơn khi đưa ra quyết định mua cổ phiếu.

\section{Biến cổ tức trên mỗi cổ phần (DPS)}

Mối quan hệ giữa EPS và SP là mối quan hệ cùng chiều, cổ tức trên mỗi cổ phiếu hay còn gọi là chính sách chia cổ tức, tỷ lệ này càng cao thì sức hấp dẫn càng lớn đối với các nhà đầu tư. Thông thường các công ty có chính sách chia cổ tức đều đặn thường là các công ty đầu ngành, có tăng trưởng đang trong quá trình chững lại và không tìm ra được những dự án đầu tư đủ hấp dẫn, vì vậy việc chia cố tức cho cổ đông là điều hiển nhiên. Qua kết quả kiểm định cho thấy giá cổ phiếu của các doanh nghiệp bất động sản được niêm yết trên sở giao dịch chứng khoán TP.HCM có tác động cùng chiều với cổ tức mỗi cồ phiếu, có thể thấy các nhà đầu tư Việt Nam ưa thích việc nhận được cổ tức khi mua cổ phiếu.

\section{KẾT LUẬN VÀ KIẾN NGH!}

\subsection{Kết luận}

Với mục tiêu nghiên cứu các yếu tố tác động đến giá cổ phiếu của các doanh nghiệp bất động sản được niêm yết trên thị trường chứng khoán Việt Nam, tôi đã tổng kết lý thuyết về các vấn đề có liên quan đển cổ phiếu, các mô hình và các nghiên cứu trước đây ở trong nước và trên thế giới làm cơ sở cho việc đề xuất mô hình nghiên cứu. Tiếp theo quá trình nghiên cứu được tiến hành thông qua phương pháp nghiên cứu định lượng kết hợp vớiphương pháp nghiên cứu định tính

Dư liệu nghiên cứu được thu thập từ 30 doanh nghiệp thuộc nhóm ngành bất động sản được niêm yết trên sở giao dịch chứng khoán TP.HCM giai đoạn 6 năm từnăm $2012-2017$.

Kết quả nghiên cứu cho thấy thu nhập trên mồi cổ phiếu (EPS), cổ tức mỗi cổ phiếu (DPS), Giá vàng (DGP) là các yếu tố có ảnh hưởng đến giá cổ phiếu của các doanh nghiệp nhóm ngành bất động sản được niêm yết trên sở giao dịch chứng khoán TP.HCM được thể hiện qua phương trình hồi quy sau:

$$
\mathrm{SP}_{\mathrm{i}, \mathrm{t}}=\text { 9.282,196 }+1,4685 \text { PPS }_{\mathrm{i}, \mathrm{t}}+2,1481 \mathrm{EPS}_{\mathrm{i}, \mathrm{t}}+13.552,93 \mathrm{DGP} \mathrm{P}_{\mathrm{i}, \mathrm{t}}+\varepsilon_{\mathrm{i}, \mathrm{t}}
$$

Kết quả nghiên cứu đã giải quyết được ba mục tiêu nghiên cứu ban đầu tác giả đề ra đó là xác định các yếu tố tác động tới giá cổ phiếu của các doanh nghiệp bất động sản được niếm yết trên thị trường chứng khoán Việt Nam. Đánh giá mức độ tác động của các yếu tố tới giá cổ phiếu của các doanh nghiệp bất động sản được niêm yết trên thị trường chứng khoán Việt Nam. Mục tiêu còn lại của đề tài là đưa ra các kết luận giúp cho nhà đầu tư có cái nhìn chiến lược hơn khi phân tích, dự báo giá cổ phiếu của các doanh nghiệp bất động sản được niêm yết trên thị trường chứng khoán Việt Nam.

\subsection{Một số kiến nghị}

\section{Đối với doanh nghiệp ngành bất động sản}

Nghiên cứu này tập trung vào các công ty thuộc nhóm ngành bất động sản được niếm yết trên sở thị trường chứng khoản Việt Nam. Thông qua kết quả nghiên cứu tôi xin đưa ra một số kiến nghị nhằm giúp cải thiện các yếu tố tác động đến giá cổ phiếu.

- Thứ nhất, theo dõi sát sao báo cáo chỉ số giá vàng trong nước. Như kết quả phân tích ở trên, chỉ số giá vàng (DGP) là yếu tố có tác động cùng chiều với giá cổ phiếu. Vì vậy các doanh nghiệp cần nên quan tâm, chú ý đến sự biến động của chỉ số này để đề ra các phương hướng hoạt động kinh doanh phù hợp, nhằm giảm thiểu rủi ro và gia tăng lợi ích tác động của yếu tố này lên giá cổ phiếu.

- Thứ hai, cần chú ý tới tỷ lệ lạm phát. Kết quả nghiên cứu cho thấy rằng tỷ lệ lạm phát có tác động ngược chiều với giá cổ phiếu, nhưng lại không có ý nghĩa thống kê. Tuy nhiên ở hầu hết các thị trường chứng khoán tỷ lệ lạm phát vẫn là một yếu tố có tác động tiêu cực đến giá cổ phiếu. Vì vậy, khi xây dựng kế hoạch sản xuất kinh doanh, các doanh nghiệp cần chủ động dự kiến được mức lạm phát tăng hay giảm trong tương lai để đưa ra được chính sách tăng giá bán các sản phẩm của mình cho phù hợp, qua đó sẽ tạo ra được những tác động tích cực đến giá cổ phiếu.

- Thứ ba, nâng cao thu nhập trên mỗi cổ phiếu (EPS). Như kết quả nghiên cứu ở chương 4 ta cũng thấy thu nhập trên mỗi cổ phiếu (EPS) có tác động cùng chiều một cách mạnh mẽ đến giá cổ phiếu. Vì vậy để gia tăng sức hấp dẫn của cổ phiếu doanh nghiệp mình, các doanh nghiệp cần có kế hoạch cụ thể để gia tăng chỉ số EPS.

+ Nâng cao khả năng điều hành quản lý của ban lãnh đạo doanh nghiệp, đây là điều kiện tiên quyết để giúp doanh nghiệp hoạt động một cách có hiệu quả nhất. Vì vậy các công ty phải luôn có các chính sách 
đãi ngộ, phúc lợi tốt để thu hút cũng như giữ chân đội ngũ lãnh đạo cũng như các nhân viên có trình độ chuyên môn tốt.

+ Có kế hoạch kinh doanh tốt, thích hợp với sự biến đổi của tình hình kinh tế vĩ mô. Tăng cường khả năng bán hàng thông qua các kênh marketing online cũng như truyền thống, bên cạnh đó cũng đưa ra các chương trình khuyến mãi mạnh tay nhằm thu hút khách hàng.

+ Tận dụng lợi thế theo quy mô để hạn chế chi phí đầu vào và đầu ra, qua đó tối đa hóa được lợi nhuận.

- Thứ tư, chính sách cổ tức hợp lý. Tỷ lệ chi trả cổ tức là yếu tố quan trọng thu hút các nhà đầu tư, qua đó tạo ra các tác động có lợi đến giá cổ phiếu. Thông qua kết quả nghiên cứu ta thấy biến cổ tức mỗi cổ phiếu (DPS) có tác động tích cực đến giá cổ phiếu. Do đó để tăng giá cổ phiếu các doanh nghiệp cần chú trọng đến tỷ lệ chi trả cổ tức hằng năm cho các cổ đông. Tuy nhiên việc chi trả nhiều hay ít thì cần phải được cân nhắc một cách kỹ lưỡng: cơ hội đầu tư trong tương lại, các rủi ro kinh doanh, tính thanh khoản và khả năng huy động vốn của doanh nghiệp.

Trên đây là một số kiến nghị đối với các doanh nghiệp nhóm ngành bất động sản được niêm yết trên thị trường chứng khoán Việt Nam nói riêng và các doanh nghiệp bất động sản nói chung trong việc duy trì và gia tăng giá cổ phiếu của doanh nghiệp.

\section{Đối với nhà đầu tư}

- Các nhà đầu tư khi lựa chọn nhóm cổ phiếu này cần có sự theo dõi, phân tích kỹ những biến động của nền kinh tế, kết quả hoạt động của các doanh nghiệp trong ngành. Đồng thời, cần so sánh các chỉ số đó với các công ty khác cùng ngành và mức bình quân của ngành, đa dạng hóa danh mục các loại cổ phiếu đầu tư để giảm thiểu rủi ro.

- Các nhà đầu tư cần phải tỉnh táo, tránh đầu tư theo xu hướng, tin đồn do rủi ro khá cao, luôn năng cao kiến thức.

- Đối với các nhà đầu tư nhỏ lẻ và chưa có nhiều kinh nghiệm, đầu tiên nên đầu tư cổ phiếu thông qua các quỹ đầu tư để học hỏi kinh nghiệm. Vì việc đầu tư của các quỹ sẽ mang tính chuyên nghiệp hơn, nên khoản đầu tư của nhà đầu tư nhỏ lẻ sẽ được an toàn hơn.

\section{Đối với Nhà nước}

Tiếp tục tái cấu trúc cơ sở hàng hóa theo hướng nâng cao chất lượng, hoàn thiện hệ thống giao dịch, hoàn thiện khung pháp lý và chính sách phát triển thị trường, ổn định các yếu tố vĩ mô nhằm đầy mạnh thu hút các nhà đầu tư nước ngoài và các nhà đầu tư tổ chức.

Cần nâng tiêu chuẩn niêm yết trên sàn nhằm nâng cao chất lượng hàng hóa niêm yết, minh bạch báo cáo tài chính của các doanh nghiệp niêm yết tránh ảnh hưởng đến uy tín chung của thị trường. Thời gian qua, các tiêu chuẩn được niêm yết trên sàn ngày càng được nâng cao theo hướng ngày càng thắt chặt. Thời gian tới, cần tiếp tục nâng cao tiêu chuẩn vốn chủ sở hữu và chỉ số ROE của công ty niêm yết.

\section{TÀI LIỆU THAM KHẢO}

1. Abdulllah, A. .M. (2014). Dividend Policy and Its impact on Stock Price-A study on Commercial Banks Listed in Dhaka Stock Exchange. Global Disclosure of Economics and Business, 3(1), 9-17..

2. Al-Tamimi \& Hussein. (2007). Factors affecting stock price in the UAE financial markets. The Business Review, 5(2), 225-223.

3. Bùi Kim Yến và Nguyễn Thái Sơn. (2014). Sự phát triển của thị trường chứng khoán VN dưới ảnh hưởng của các nhân tố kinh tế vĩ mô. Tạp chí Phát triển và Hội nhập, 16 (26), 3-10.

4. Nguyễn Minh Kiều. (2009). Tài chính doanh nghiệp căn bản. TP.HCM: Nhà xuất bản thống kê.

5. Phạm Trí Cao và Vũ Minh Châu. (2009). Kinh tế lượng ứng dụng. TP.HCM: Nhà xuất bản Thống kê.

6.Tạp chí Tài chính số 18 kỳ 1-2018. Truy xuất từ http://epaper.tapchitaichinh.vn /tctc_1_8_2018/files/assets/basic-html/page2.html.

7. Thân Thị Thu Thủy và Võ Thị Thùy Dương. (2015). Sự tác động của các nhân tố kinh tế vĩ mô đến các chỉ số giá cổ phiếu tại HOSE. Tạp chí phát triển và hội nhập, 24(34), 59-67. 


\section{CÁC YẾU TỐ ẢNH HƯỞNG ĐẾN GIÁ CỔ PHIẾU CỦA NHƯNG DOANH NGHIỆP BẤT ĐỘNG SẢN NIÊM YẾT TRÊN THỊ TRƯỜNG CHỨNG KHOÁN VIẸT NAM}

8.Thị trường chứng khoán 2017. Truy xuất từ http://thoibaotaichinhvietnam.vn /pages/chung-khoan/2017-12-22/thi-truong-chung-khoan-2017-ket-qua-ngoai-mong -doi-51833.aspx.

9. Truy xuất từ https://nhipcaudautu.vn/bat-dong-san/buc-tranh-doanh-thu-va-loi-nhuan-nganh-bat-dong-san-nam2018-3328194.html

10. Trích xuất từ https://nhadat.tuoitre.vn/2018-2019-bung-no-dau-tu-vao-bat-dong-san-tai-viet-nam$\underline{20190614140036316 . h t m l}$

11. Truy xuất từ http://kinhtedothi.vn/fdi-dau-tu-vao-bat-dong-san-von-lon-nhung-vuong-chinh-sach-352579.html

12. Trương Đông Lộc .(2014). Các nhân tố ảnh hưởng đến sự thay đổi giá của cổ phiếu. Các bằng chứng từ sở giao dịch chứng khoán TP.HCM. Tạp chí Khoa học truò̀ng ĐH Cần Tho, 33(2014), $72-78$.

13. Verma, O.P., Sharma., \& Sanjeet,. (2011). Macro Economic Indicators and Stock Prices: Evidence from Indian Stock Market. Kegees Journal of Social Science, 3(2), 266-272.

14. Uddin, M. R., Rahman, S.Z., \& Hossan, M.R. (2013). Determainants of Stock Priecs in Financial Sector Companies in Bangladesh: A study on Dhaka Stock Exchange (DSE). Interdisciplinary Journal of Contemporary Research in Business, 5(3), 471-480.

15. Umar, G., \& Ishiak, O. I. (2009). Environmental Factors Influencing Fluctuation of Share Prices on Nigeria Stock Exchange Market. An International Multi-Disciplinary Journal, 3(5), 199-212.

Ngày nhận bài: 02/12/2019 Ngày chấp nhận đăng:24/03/2020 